Article

\title{
Structural Integrity Evaluation of a Reactor Cavity during a Steam Explosion for External Reactor Vessel Cooling
}

\author{
Sang-Hyun Park (D), Kwang-Hyun Bang and Jong-Rae Cho *(D) \\ Division of Mechanical Engineering, Korea Maritime \& Ocean University, Busan 49112, Korea; \\ say100dlf@naver.com (S.-H.P.); khbang@kmou.ac.kr (K.-H.B.) \\ * Correspondence: cjr@kmou.ac.kr
}

check for updates

Citation: Park, S.-H.; Bang, K.-H.;

Cho, J.-R. Structural Integrity

Evaluation of a Reactor Cavity during a Steam Explosion for External

Reactor Vessel Cooling. Energies 2021,

14, 3605. https://doi.org/10.3390/

en14123605

Academic Editor: Ricardo J. Bessa

Received: 19 April 2021

Accepted: 16 June 2021

Published: 17 June 2021

Publisher's Note: MDPI stays neutral with regard to jurisdictional claims in published maps and institutional affiliations.

Copyright: (c) 2021 by the authors. Licensee MDPI, Basel, Switzerland. This article is an open access article distributed under the terms and conditions of the Creative Commons Attribution (CC BY) license (https:/ / creativecommons.org/licenses/by/ $4.0 /)$.

\begin{abstract}
Nuclear power is a major source of electricity in the international community. However, a significant problem with nuclear power is that, if a severe nuclear accident occurs, radiation may leak and cause great damage. As such, research on nuclear safety has become increasingly popular worldwide. In this paper, the structural integrity of a reactor cavity during a steam explosion-one kind of the aforementioned severe nuclear accidents—-was evaluated. Steam explosions are primarily caused by fuel-coolant interactions (FCI), and result from issues in the cooling system that discharges the melt from the reactor core to the outside. A steam explosion can damage the nuclear power plant, and radiation leakage, the greatest concern, may occur. In the Chernobyl or Fukushima Daiichi accidents, significant radiation leakages resulted in damages extending beyond the country of origin. In this paper, a steam explosion was simulated using values given by the transient analysis code for explosive reactions (TRACER-II) - the only steam explosion code in Korea. The walls of the reactor cavity were modeled after the APR-1400 currently operating in Korea. The integrity of the concrete, rebars, and liner plate in the reactor cavity during a steam explosion was evaluated in terms of stress and ductile failure strain limits.
\end{abstract}

Keywords: nuclear power plant; reactor cavity; steam explosion; structural integrity

\section{Introduction}

According to the International Nuclear and Radiological Event Scale (INES) [1], a severe accident is defined as one that goes beyond a design-basis accident and causes core damage. In general, if the decay heat in the core cannot be reduced owing to complications in the coolant system, a temperature rise may melt and damage the cladding, causing a severe accident. A typical example is the nuclear meltdown that occurred in 1979 at the Three Mile Island Unit 2 reactor, Pennsylvania. This accident was caused by a core meltdown due to a violation of the procedure guidelines, defects in the facility, and repeated operator mistakes [2]. Fortunately, the reoperation of the coolant pump prevented significant radiation leakage. However, the accident was rated a level 5 on INES. Thenceforth, various procedures have been improved upon, including the reinforcement of education directives for strengthening the human element internationally. In addition, designs that reinforced human-machine connectivity have been implemented as follow-up measures.

In the wake of the 2011 Great East Japan Earthquake, a large tsunami occurred, which resulted in the flooding of an emergency diesel generator at the Fukushima Daiichi nuclear power plant during a blackout. Eventually, a station blackout (SBO) was declared. Consequently, the coolant remaining in the plant was unable to withstand the decay heat and evaporated entirely. The melt in the core was subsequently released from the reactor vessel. Subsequently, hydrogen was generated by the zirconium in the nuclear fuel. Eventually, an accumulation of hydrogen in the containment building resulted in an explosion [3]. This event has been rated at the highest INES level of 7, and it continues to leak radiation. 
As a follow-up measure, the Republic of Korea adopted an approach to control hydrogen levels that uses a combustion igniter to prevent hydrogen explosions in nuclear power plants. In addition, a passive autocatalytic recombiner (PAR) was installed in the APR-1400 that is currently in operation and receiving orders. Moreover, the APR-1400 uses in-vessel retention through external reactor vessel cooling (IVR-ERVC) as a cooling strategy. Steam explosions occur in four steps: mixing, triggering, propagation, and expansion. Extensive research has been conducted to simulate a realistic steam explosion [4,5]. In Korea, a real steam explosion was tested using the test for real corium interaction with water (TROI), conducted by the Korea Atomic Energy Research Institute (KAERI) [6]. Similarly, in the United States, extensive simulation studies on steam explosions are conducted through FARO (furnace additionally, release oven) experiments [7] and KROTOS experiments [8] at the Sandia National Laboratories. In addition, the PM-ALPHA/ESPROSE [9] and MC3D [10] codes have been developed for steam explosion analysis. The TEXAS-V (thermal explosion analysis simulation-V) code is widely used for verification in Korea [11-13].

This study aims to develop a computational model using the FEM for the nonlinear analysis of reinforced concrete in the reactor cavity in the event of a steam explosion and to verify structural integrity. The advantage of FE modeling is that it can use the element-embedded rebar model in ANSYS, with its 3D quadratic element SOLID186 for the discretization of the concrete and the element REINF264 for the discretization of rebars, making the modeling and solution more efficient. Kim et al. [14,15] evaluated the structure of reinforced concrete in the reactor cavity but used the results of one-dimensional TEXAS$\mathrm{V}$ for assessing explosion pressure. In this study, the integrity of the reactor cavity wall was evaluated based on the pressure history obtained from the TRACER-II code [16] developed by Korea Maritime and Ocean University.

\section{Finite Element Modeling}

\subsection{Structure Modeling and Element}

The walls of a reactor cavity in a nuclear power plant are reinforced concrete structures, with many rebars in the concrete. Figure 1 shows the walls of the reactor cavity in Korea's APR-1400, which was modeled on the information available from such sources as the APR-1400 Design Control Document (DCD) [15]. Figure 2 shows the arrangement of rebars in the structure. The numbers \#11,\#14, and \#18 in Figure $2 \mathrm{~b}$ represent the rebar sizes. The rebars were modeled after beam elements in the finite element (FE) analysis. Figure 3 shows the structure of the FE meshes.

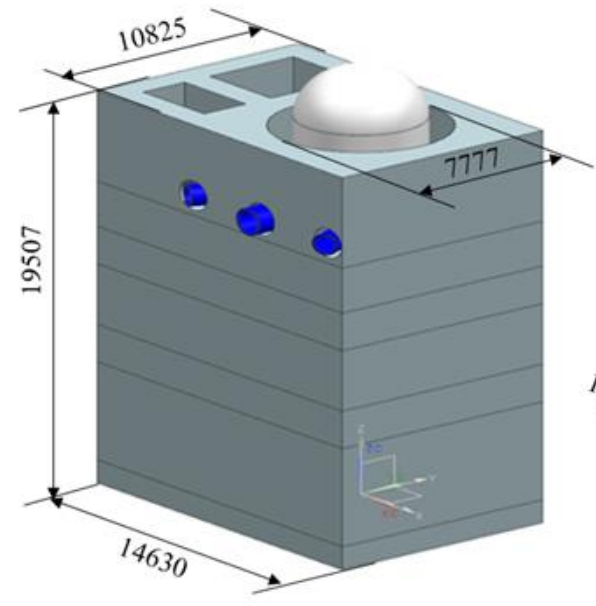

(a)

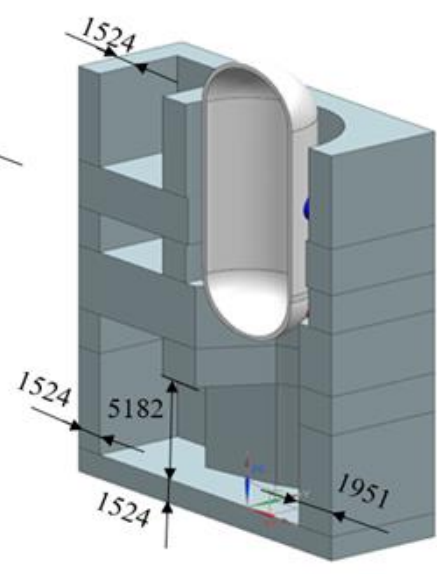

(b)

Figure 1. Modeling of the walls of the reactor cavity. (a) The overall shape of the reactor cavity. (b) The interior of the reactor cavity. 


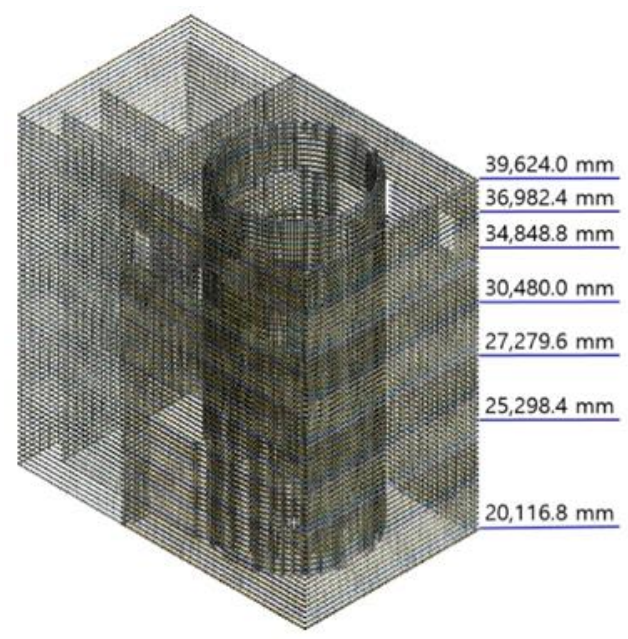

(a)

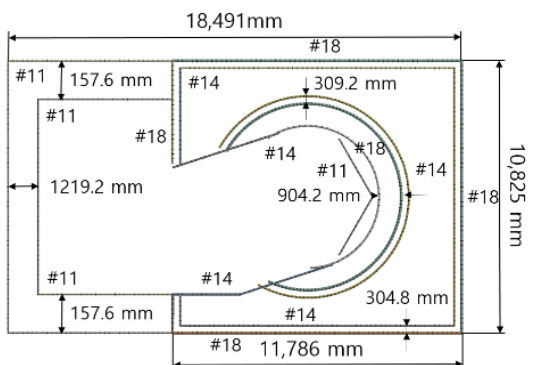

(b)

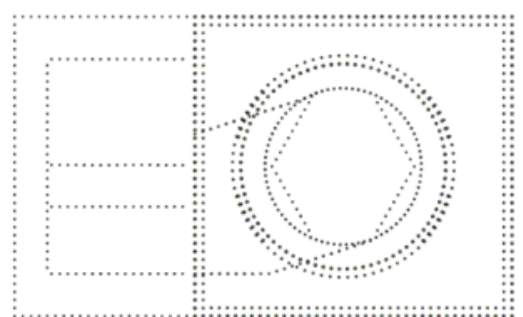

(c)

Figure 2. Schematic diagram showing the arrangement of the rebars. (a) The overall arrangement of the rebars and height information. (b) The horizontal arrangement at heights in the 20,116-25,298 mm range. (c) The vertical arrangement of the rebars.

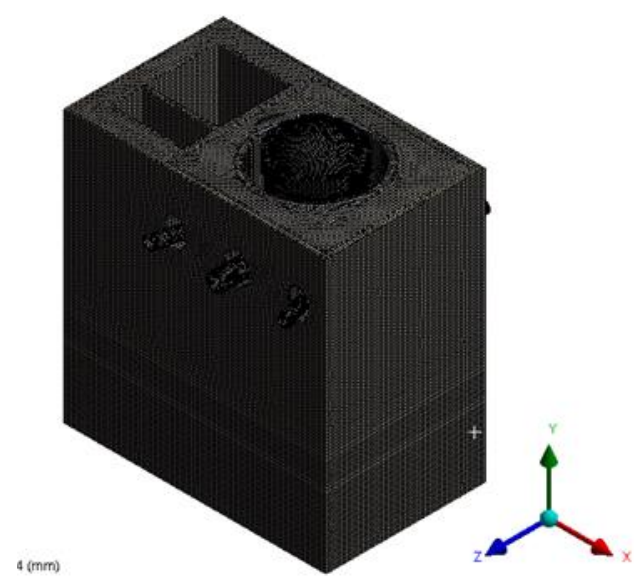

Figure 3. Finite element (FE) mesh for the reactor and the containment building.

In the FE modeling of concrete reinforced with steel rebar, concrete is generally modeled as a three-dimensional solid, and there are three available methods, depending on how the rebar is modeled: solid elements, three-dimensional spar elements, or embedded elements. If a mesh is constructed using only solid elements, the number of elements increases due to the high mesh density in the contacting and curved parts, and modeling this takes a lot of time. If spar elements are used, modeling takes a lot of time because all the nodes are shared. When embedded elements are applied, modeling is relatively simple, because only the elements are shared, and not the nodes. In this study, FE modeling using embedded elements was employed for the first time in reactor cavity analysis. 


\subsection{Material Properties}

In this study, the material properties were verified using information obtained from the APR-1400 DCD data [17] published by the Nuclear Regulatory Commission (NRC). Table 1 shows the material properties of concrete, namely, the compressive and tensile strengths. Table 2 shows the material properties of the liner plate (ASTM A516 Grade 60), and Table 3 shows the material properties of the rebars (A615 Grade 60).

Table 1. Material properties of concrete.

\begin{tabular}{cc}
\hline Property & Value \\
\hline Young's modulus (GPa) & 30.4 \\
Poisson's ratio & 0.17 \\
Compressive strength (MPa) & 41.4 \\
Tensile strength (MPa) & 4.83 \\
\hline
\end{tabular}

Table 2. Material properties of ASTM SA516 Grade 60.

\begin{tabular}{cc}
\hline Property & Value \\
\hline Young's modulus (GPa) & 200 \\
Poisson's ratio & 0.3 \\
Yield strength (MPa) & 220 \\
Tensile strength (MPa) & 415 \\
\hline
\end{tabular}

Table 3. Material properties of ASTM A615 Grade 60.

\begin{tabular}{cc}
\hline Property & Value \\
\hline Young's modulus (GPa) & 210 \\
Poisson's ratio & 0.3 \\
Yield strength (MPa) & 420 \\
Tensile strength (MPa) & 620 \\
\hline
\end{tabular}

\subsection{Concrete Yield Criteria Model}

The Drucker-Prager and Menetrey-Willam models [18] were adopted in this study for the concrete.

The equations for the Ducker-Prager model are as follows:

$$
\begin{gathered}
f_{D P_{t}}=\frac{\sigma_{e}}{\sqrt{3}}+\beta_{t} \sigma_{m}-\sigma_{Y t} \\
f_{D P_{c}}=\frac{\sigma_{e}}{\sqrt{3}}+\beta_{c} \sigma_{m}-\sigma_{Y c} \Omega_{c}
\end{gathered}
$$

In the Drucker-Prager model, the yield surfaces under tension and compression are defined as in Equations (1) and (2), respectively. Here, the subscripts $t$ and $c$ represent tension and compression, respectively. $\sigma_{e}$ and $\sigma_{m}$ are the von Mises and mean stress, and $\beta_{t}$ and $\sigma_{Y t}$ are constants derived from the uniaxial tensile and compressive strengths, respectively. $\beta_{\mathcal{C}}$ and $\sigma_{Y_{c}}$ are related to the uniaxial and biaxial compressive strengths. $\Omega_{\mathcal{C}}$ is the hardening or softening function under compression.

The equation for the yield surface in the Menetrey-Willam model is as follows:

$$
f_{M W}=\frac{c_{1}}{c_{2}}[\sqrt{2} \xi+r \rho]+\rho^{2}-\frac{1}{c_{2}}
$$

Here, $c_{1}, c_{2}$ and $r$ are determined by the tensile and compressive strengths and the softening or hardening function due to these strengths. $\xi$ and $\rho$ are determined using the first principal stress and the second principal invariant of the tensor, respectively. 
In this paper, two models were selected and analyzed for a more conservative evaluation.

\section{Applied Explosive Pressure}

A steam explosion, a phenomenon that involves very high pressure and strong shock waves, typically occurs between the melt and the coolant. It is also referred to as the aforementioned FCI. Steam explosions caused by severe accidents at nuclear power plants are classified into two types: incore and excore. In an incore steam explosion, core melt is induced by a reaction with the coolant remaining in the lower plenum of the reactor vessel. The reactor vessel may be damaged due to the pressure generated by the explosion, and the resulting debris may impact the structural integrity of the reactor. In an excore steam explosion, which is discussed in this study, the excore melt flows into the reactor cavity, reacting with the cooling water in it to cause a steam explosion. The resulting pressure can damage structures, such as the walls of the reactor cavity. Steam explosions occur in a four-step process: mixing, triggering, propagation, and expansion. In this study, the TRACER-II was developed to analyze both the mixing and explosion processes of steam explosions resulting from FCI. The mathematical model consisted of continuity, momentum, energy, and interaction equations for a multiphase flow. Figure 4 shows the IVR-ERVC state with the reactor cavity filled with coolant before the steam explosion. Figure 5 shows the pressure waves for different reference heights of the steam explosion location over time using the TRACER-II. In this study, the structural integrity of the walls of the reactor cavity during a steam explosion was evaluated through an implicit analysis of this pressure wave.

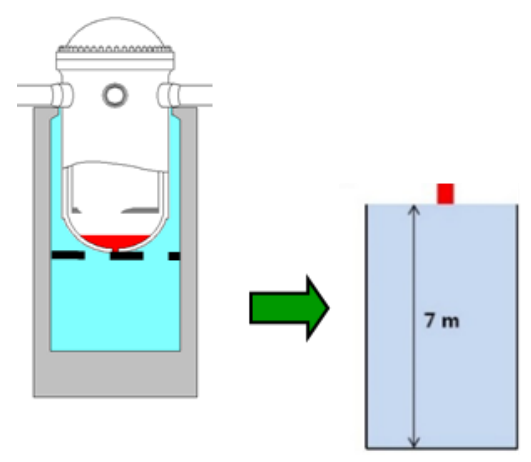

Figure 4. Schematic diagram of the IVR-ERVC state of the reactor cavity before the excore steam explosion.

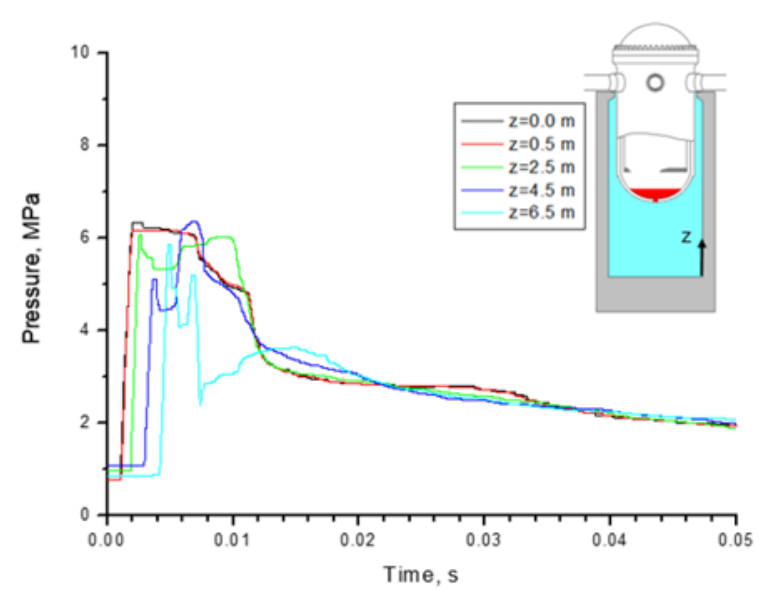

Figure 5. Steam explosion pressure history for different heights derived from the TRACER-II. 


\section{Structural Integrity Evaluation Using Finite Element Method \\ 4.1. Boundary and Load Conditions}

The walls of the nuclear cavity are arranged on the floor, and the pressure data of a steam explosion from the TRACER-II, mentioned in Section 4, were considered for the load condition. This load condition varied with the height, and the analysis was performed for up to $0.05 \mathrm{~s}$ using TRACER-II. Figure 6a shows a fixed support installed at the bottom. Figure $6 \mathrm{~b}$ shows that the pressure applied depends on the height of the lower part of the reactor in the reactor cavity.

$\square$ Fixed Support

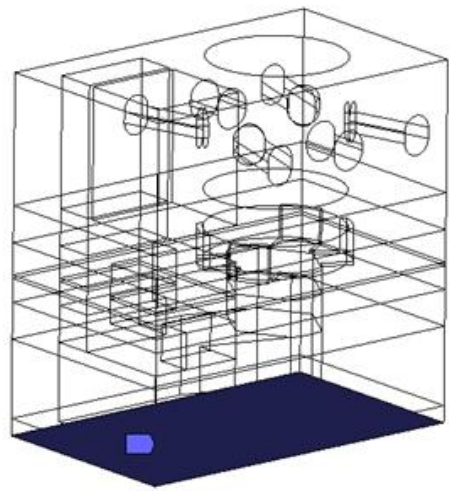

(a)

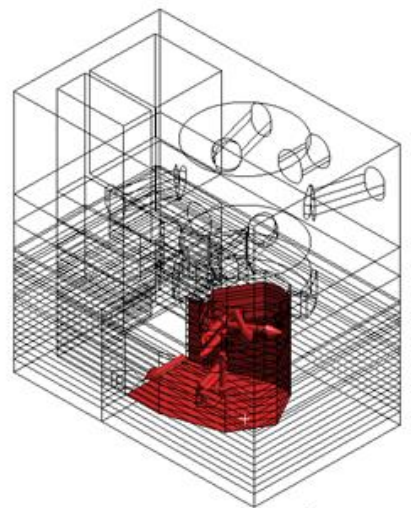

(b)

Figure 6. (a) Boundary conditions for structural analysis. (b) Load conditions for structural analysis.

\subsection{Evaluation Method}

A steam explosion is a phenomenon that corresponds to impact analysis, whereby a large amount of pressure is generated quickly due to FCI. When analyzing such a phenomenon, the dynamic increase factor (DIF) is considered by referring to the NEI 07-13 [19] data, as shown in Table 4, published by the ACI-349 [20] and the Nuclear Energy Institute (NEI). This is not specific to concrete, and can also be applied to the rebars and liner plates. Indices indicating the limits for the strength and strain are detailed in NEI 07-13.

Table 4. Dynamic increase factor (DIF).

\begin{tabular}{ccc}
\hline \multirow{2}{*}{ Material } & \multicolumn{2}{c}{ DIF } \\
\cline { 2 - 3 } & Yield Strength & Ultimate Strength \\
\hline Concrete & - & 1.12 \\
A516 Gr. 60 & 1.12 & 1.05 \\
A615 Gr. 60 & 1.10 & 1.05 \\
\hline
\end{tabular}

Structural integrity in concrete is evaluated by comparing the maximum tensile and compressive stress with the tensile and compressive strength, respectively. For rebar and liner plates, the maximum von Mises stress should not exceed the yield strength. The ductile failure strain limit should be verified for the resulting physical, fire, and impact effects [18]. Table 5 shows the limiting values of the ductile failure strain for the rebars and liner plate.

Table 5. Ductile failure strain limits.

\begin{tabular}{ccc}
\hline Material & Strain Measure & Limiting Value \\
\hline A516 Gr. 60 & Membrane principal strain & 0.05 \\
A615 Gr. 60 & Tensile strain & 0.05 \\
\hline
\end{tabular}




\subsection{Results}

\subsubsection{Concrete}

The behavior of concrete varies depending on the compression and tension. The principal stress is evaluated mainly during construction, and a notable characteristic of concrete is that its tensile strength is weaker than its compression strength. During our analysis, the effect of tension was examined based on the primary maximum principal stress. The maximum principal stress over time of the concrete used in the walls of the reactor cavity was $8.06 \mathrm{MPa}$ in the Drucker-Prager model, as shown in Figure 7a, and 7.03 MPa in the Menetrey-Willam model, as shown in Figure $7 \mathrm{~b}$. Figure 8 shows the distribution of the principal stresses for each model. The maximum principal stress occurred at $6.77 \times 10^{-3} \mathrm{~s}$ in the Drucker-Prager model and at $5.80 \times 10^{-3} \mathrm{~s}$ in the Menetrey-Willam model. Figure 9 details the maximum principal stress distribution of the concrete in the damaged parts of the walls of the reactor cavity.

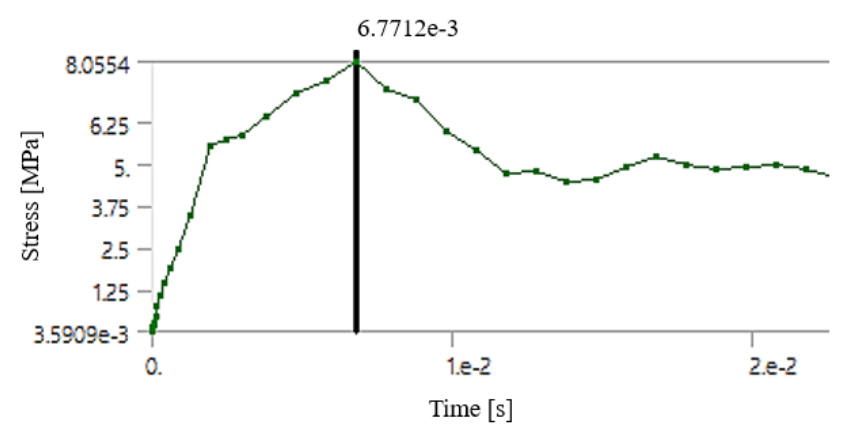

(a)

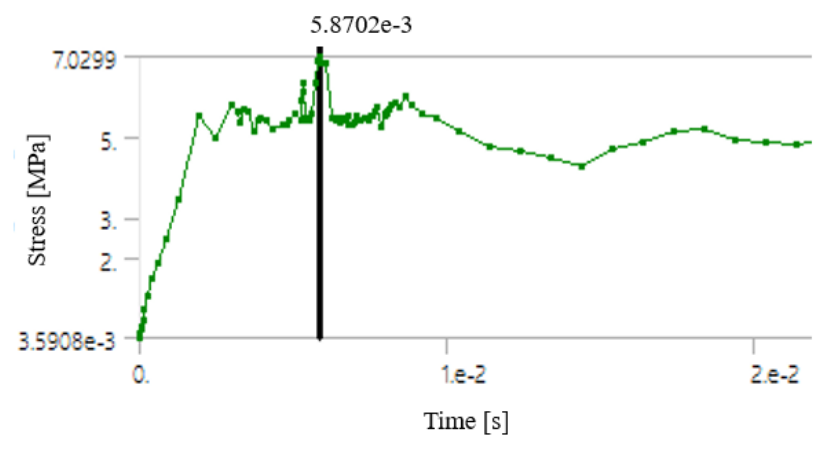

(b)

Figure 7. Principal stress history in cavity wall concrete with time. (a) The Drucker-Prager model. (b) The Menetrey-William model.

\subsubsection{Rebar}

From the rebar analysis, the von Mises stresses were $291 \mathrm{MPa}$ in the Drucker-Prager model and $285 \mathrm{MPa}$ in the Menetrey-Willam model. The strains were very low at $1.42 \times 10^{-3}$ and $1.46 \times 10^{-3}$ for the Drucker-Pager and Menetrey-William models, respectively.

\subsubsection{Liner Plate}

Figure 10 shows the analysis results for the liner plate. The von Mises stresses in the Drucker-Prager model, as shown in Figure $10 \mathrm{a}$, were $186 \mathrm{MPa}$ at $8.77 \times 10^{-3} \mathrm{~s}$, and they were $208 \mathrm{MPa}$ at $9.20 \times 10^{-3} \mathrm{~s}$ in the Menetrey-Willam model, as shown in Figure 10b. Figure 11 shows the distribution of the membrane principal strain of the liner plate, the maximum values of which were $4.08 \times 10^{-4}$ at $7.71 \times 10^{-3} \mathrm{~s}$ in the Drucker-Prager model, as shown in Figure 11a, and $4.17 \times 10^{-4}$ at $9.20 \times 10^{-3} \mathrm{~s}$ in the Menetrey-Willam model, as shown in Figure 11b. 


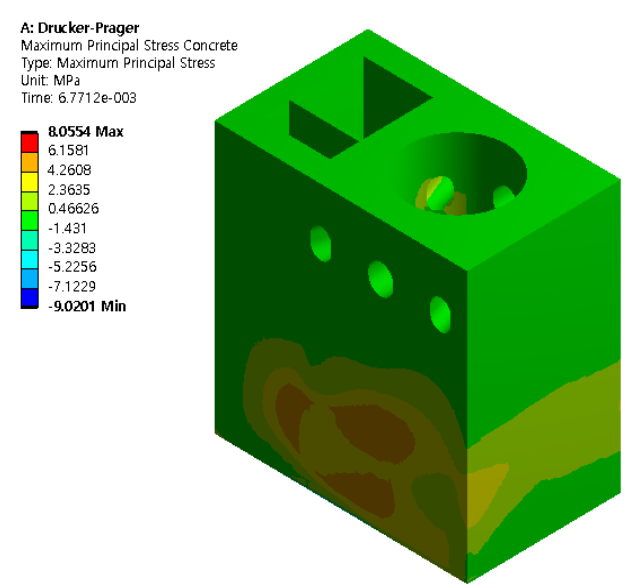

(a)

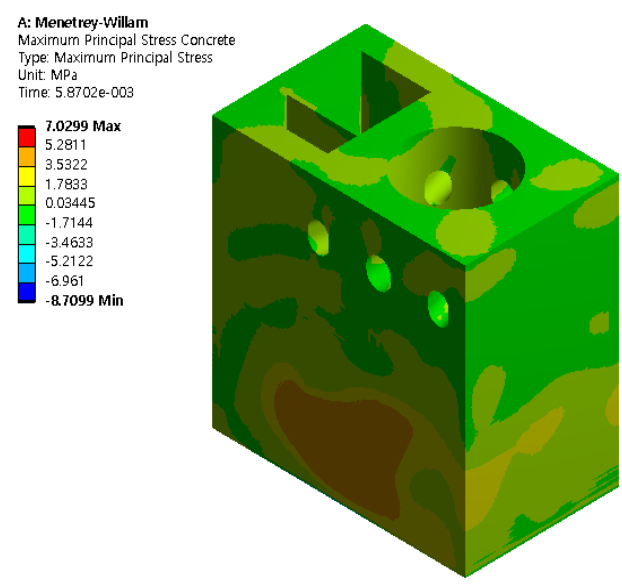

(b)

Figure 8. Maximum principal stress distribution in the concrete walls. (a) The Drucker-Prager model. (b) The MenetreyWilliam model.

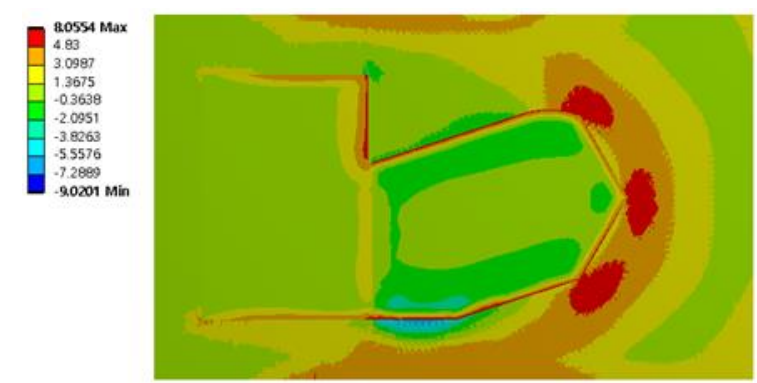

(a)
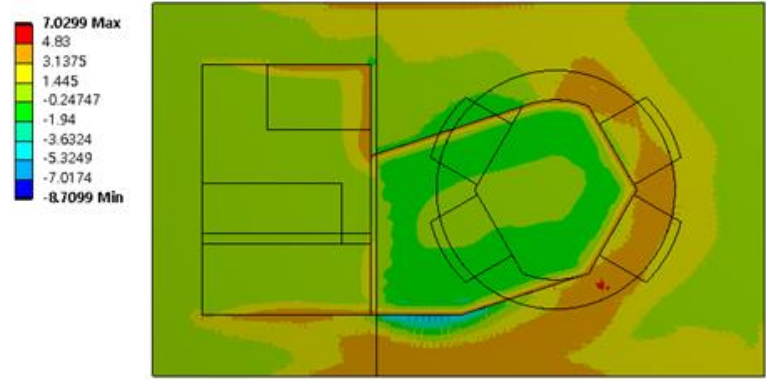

(b)

Figure 9. Maximum principal stress distribution in the damaged regions of the concrete walls. (a) The Drucker-Prager model. (b) The Menetrey-William model.

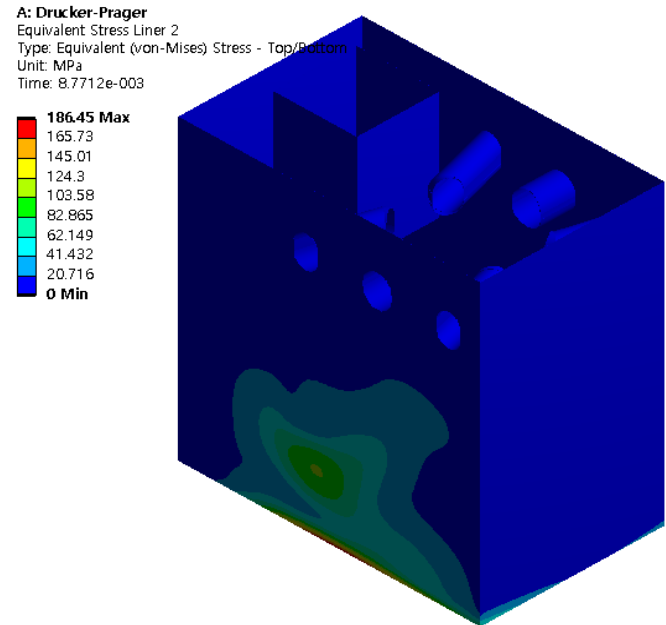

(a)

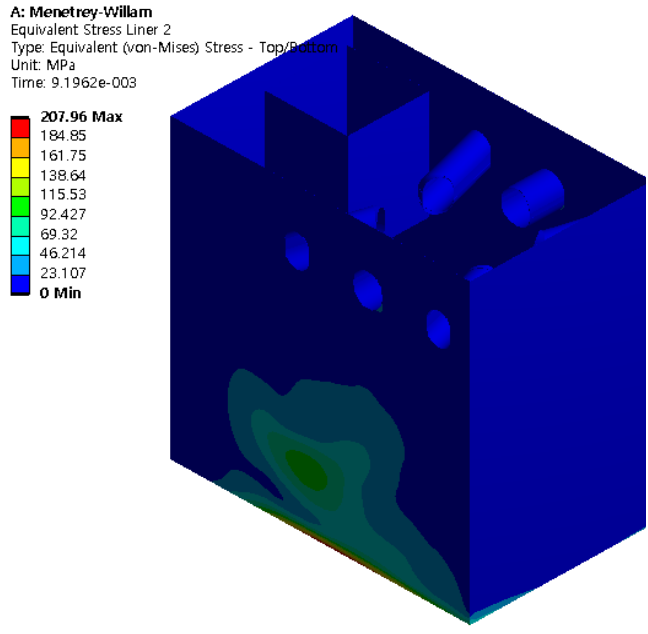

(b)

Figure 10. Von Mises stress distribution in the liner plate. (a) The Drucker-Prager model. (b) The Menetrey-William model. 


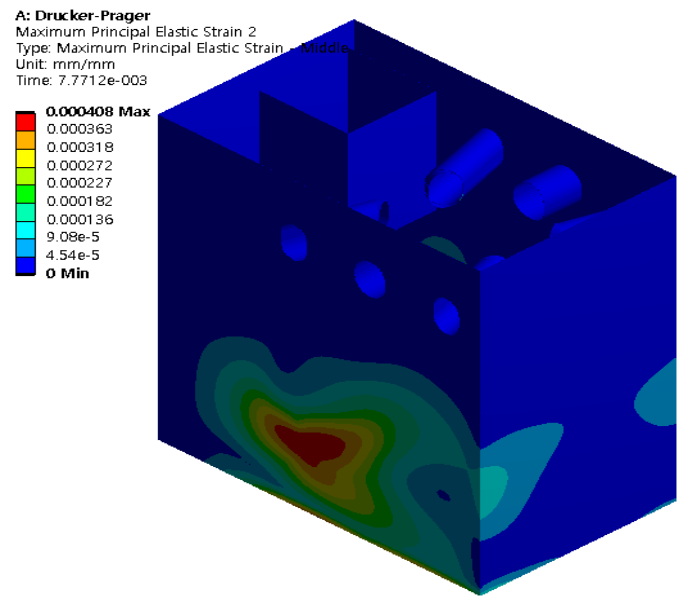

(a)

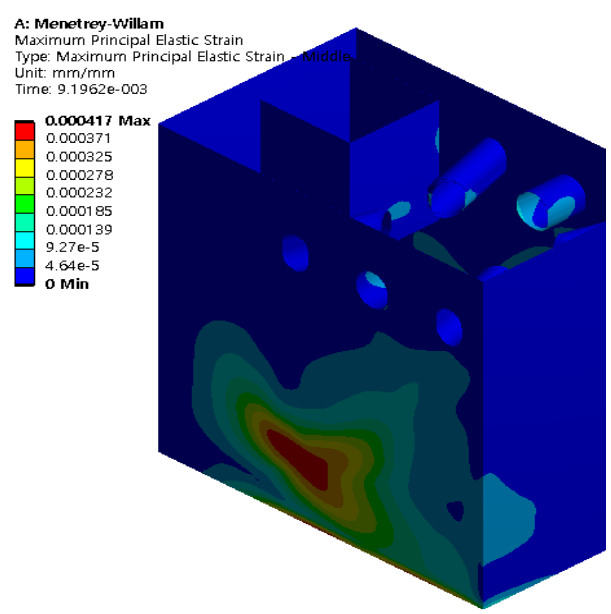

(b)

Figure 11. Membrane principal strain distribution in the liner plate. (a) The Drucker-Prager model. (b) The MenetreyWilliam model.

\subsubsection{Evaluation by Failure Category}

From the analysis results for each failure category, Table 6 shows the stress as evaluated when DIF was applied. The cavity inside the concrete could be broken because the tensile stress exceeded the tolerable tensile stress for concrete. However, the area where the tensile stress exceeding the tensile strength occurs is narrow and local compared to the thickness of the cavity wall, and that acting on all the rebars was lower than the tolerable level; therefore, the soundness of the concrete was maintained. Additionally, there was no significant difference in stress according to the concrete yield criteria model. When considering the strain evaluation based on the ductile failure strain limits, the rebar and liner plate corresponding to the ductile material were within the limits, ensuring integrity (Table 7).

Table 6. Structural integrity evaluation of stress.

\begin{tabular}{ccccc}
\hline \multirow{2}{*}{ Location } & Stress Category & \multirow{2}{*}{ Allowable Limit (MPa) } & \multicolumn{2}{c}{ Calculated Stress (MPa) } \\
\cline { 4 - 5 } & & & Drucker-Prager & Menetrey-William \\
\hline \multirow{2}{*}{ Reactor cavity } & Maximum tensile stress & 4.83 & 8.06 & 7.03 \\
Liner plate & Minimum compressive stress & 41.4 & 30.6 & 35.9 \\
Rebar & Von Mises stress & 220 & 186 & 208 \\
\hline
\end{tabular}

Table 7. Ductile failure strain limits.

\begin{tabular}{cccc}
\hline Material & Strain Category & Limiting Value & Calculated Value \\
\hline A516 Gr. 60 liner plate & Membrane principal strain & 0.050 & 0.00104 \\
\hline A615 Gr. 60 rebar & Tensile strain & 0.050 & 0.00185 \\
\hline
\end{tabular}

\section{Conclusions}

In this study, the structural integrity of the walls of a reactor cavity during a steam explosion was evaluated for IVR-ERVC. The nuclear power plant was based on the APR-1400 model, and the pressure history obtained from the TRACER-II was applied to determine the transient pressure loading conditions.

From this analysis, we found that there was no significant difference in the stress results according to the concrete yield criteria model. However, it was confirmed that the Drucker-Prager model in concrete had larger tensile stress and a wider range than the 
Menetrey-William model. We believe that very few cracks occurred in the concrete walls due to tensile stress. However, the depth of the crack is narrow and local compared to the thickness of the cavity wall and the liner plate was also sound, and the integrity of the rebar was secured in some of the damaged regions that occurred in the concrete. Herein, the structural integrity of a reactor cavity during a simulated steam explosion was evaluated accurately.

Author Contributions: Conceptualization, K.-H.B. and J.-R.C.; methodology, J.-R.C.; software, S.H.P.; validation, S.-H.P. and J.-R.C.; formal analysis, S.-H.P.; investigation, J.-R.C.; resources, S.-H.P.; data curation, S.-H.P.; writing-original draft preparation, S.-H.P.; writing-review and editing, J.-R.C.; visualization, S.-H.P.; supervision, J.-R.C.; project administration, K.-H.B.; funding acquisition, K.-H.B. All authors have read and agreed to the published version of the manuscript.

Funding: This study was funded by the Nuclear Safety and Security Commission (NSSC), Republic of Korea (No. 1803012).

Institutional Review Board Statement: Not applicable.

Acknowledgments: This study was supported by the Nuclear Safety Research Program of the Korea Foundation of Nuclear Safety (KoFONS).

Conflicts of Interest: The authors declare no conflict of interest.

\section{References}

1. IAEA. International Nuclear and Radiological Event Scale User's Manual, 2008th ed.; IAEA: Vienna, Austria, 2013.

2. U.S. Nuclear Regulatory Commission. Background on the Three Miles Island Accident. Available online: https://www.nrc.gov / reading-rm/doc-collections / fact-sheets/3mile-isle.html (accessed on 6 May 2021).

3. Wikipedia. Fukushima Daiichi Nuclear Disaster. Available online: https://en.wikipedia.org/wiki/Fukushima_Daiichi_nuclear_ disaster (accessed on 6 May 2021).

4. Leskovar, M.; Uršič, M. Ex-vessel steam explosion analysis for pressurized water reactor and boiling water reactor. Nucl. Eng. Technol. 2016, 48, 72-86. [CrossRef]

5. Zhang, L. Mechanism-based codes for severe accident analysis. In Nuclear Power Plant Design and Analysis Codes; Woodhead Publishing Series in Energy; Woodhead Publishing: Sawston, UK, 2021; pp. 333-360.

6. Kim, S.H.; Hong, S.W.; Park, R.J. Comparison of Triggered Steam Explosion Behavior According to Corium Injection Mode in TROI Facility from TEXAS-V Code Simulations. Nucl. Technol. 2021, 1-18. [CrossRef]

7. Magallon, D.; Hohman, H. High pressure corium melt quenching tests in FARO. Nucl. Eng. Des. 1995, 155, 253-270. [CrossRef]

8. Zabiego, M.; Brayer, C.; Grishchenko, D.; Dajon, J.B.; Fouquart, P.; Bullado, Y.; Piluso, P. The KROTOS KFC and SERENA/KS1 tests: Experimental results and MC3D calculations. In Proceedings of the 7th International Conference on Multiphase Flows (ICMF), Tampa, FL, USA, 30 May-4 June 2010.

9. Fletcher, D.F. A comparison of coarse mixing predictions obtained from the CHYMES and PM-ALPHA models. Nucl. Eng. Des. 1992, 135, 419-425. [CrossRef]

10. Sairanen, R.; Berthoud, G.; Ratel, G.; Meignen, R.; Jacobs, H.; Buerger, M.; Vitanza, C. OECD Research Programme on Fuel-Coolant Interaction Steam Explosion Resolution for Nuclear Applications-SERENA; Final Report; Organisation for Economic Co-Operation and Development: Paris, France, 2007.

11. Cizelj, L.; Koncar, B.; Leskovar, M. Vulnerability of a partially flooded PWR reactor cavity to a steam explosion. Nucl. Eng. Des. 2006, 236, 1617-1627. [CrossRef]

12. Kim, S.H.; Chang, Y.S.; Song, S.; Cho, Y.J. Structural assessment of fully flooded reactor cavity and penetration piping under steam explosion conditions. Int. J. Press. Vessel. Pip. 2015, 131, 36-44. [CrossRef]

13. Chu, C.C.; Corradini, M.L. One-Dimensional Transient Fluid Model for Fuel/Coolant Interaction Analysis. Nucl. Sci. Eng. 1989, 101, 48-71. [CrossRef]

14. Kim, S.H.; Chang, Y.S.; Cho, Y.J. Parametric analyses of major nuclear components and reinforced concrete structures under FCI-induced explosive condition. Nucl. Eng. Des. 2017, 322, 148-158. [CrossRef]

15. Kim, S.H.; Chang, Y.-S.; Cho, Y.-J.; Jhung, M.J. Modeling of reinforced concrete for reactor cavity analysis under energetic steam explosive condition. Nucl. Eng. Technol. 2016, 48, 218-227. [CrossRef]

16. Bang, K.-H.; Kim, H.-T.; Tan, V.D. Experiment and modeling of jet breakup in fuel-coolant interactions. Ann. Nucl. Energy 2018, 118, 336-344. [CrossRef]

17. U.S. Nuclear Regulatory Commission. APR1400 Design Control Document and Environmental Report. 2018. Available online: https:/ / www.nrc.gov/reactors/new-reactors/design-cert/apr1400/dcd.html (accessed on 6 May 2021).

18. Muthukumar, G.; Kumar, M. Failure criteria of concrete-A review. Comput. Concr. 2014, 14, 503-526. [CrossRef] 
19. NEI USA. Methodology for Performing Aircraft Impact Assessments for New Plant Designs; NEI 07-13 Revision; ERIN Engineering \& Research, Inc.: Walnut Creek, CA, USA, 2011.

20. ACI Committee. Code Requirements for Nuclear Safety-Related Concrete Structures; An ACI Standard; American Concrete Institute: Farmington Hills, MI, USA, 2013. 